\title{
Realidad y ficción en la obra de Mario Vargas Llosa ${ }^{1}$
}

Roy Alfaro Vargas ${ }^{2}$

Universidad de Costa Rica

\section{RESUMEN}

Se explica la utilización de las categorías de realidad-ficción, como procedimiento para estructurar el texto narrativo o teatral por parte de Mario Vargas Llosa. El análisis asume la relación de esta técnica literaria con el paradigma posmoderno y con la ideología neoliberal, con lo cual muestra la importancia de la noción de tiempo para la conjunción de estos elementos.

\section{Abstract}

An explanation is given of the use of the categories of reality and fiction, as a way of organizing Vargas Llosa's narrative and theatrical texts. This analysis assumes the relationship between this literary technique and postmodernism and neo-liberalism, with relation to the notion of time.

Palabras clave: literatura hispanoamericana, posmodernidad, realidad, ficción, Mario Vargas Llosa

Keywords: Spanish American literature, postmodernity, reality, fiction, Mario Vargas Llosa

\section{Introducción}

Para el análisis del binomio realidad-ficción en la literatura de Mario Vargas Llosa, se parte de que tal binomio responde a una

Recibido: 28 de agosto de 2008; aceptado: 10 de octubre de 2009.

Correo electrónico: royalfarov@gmail.com 
concepción política neoliberal, anclada en el paradigma posmoderno y que presupone a un lector pasivo como receptor de su ideología, en tanto ente manipulable.

En este artículo se caracteriza de modo general la escritura de Vargas Llosa; se describe el papel del binomio realidad-ficción, en cuanto técnica fundamental de la obra vargasllosiana; se señala cómo se emplea tal técnica en Kathie y el hipopótamo y en Lituma en Los Andes; se identifica la relación entre tal técnica y el paradigma posmoderno; se definen los parámetros ideológicos que sustentan la estructuración textual en realidad y ficción; y se establecen críticamente los valores y esquemas cognitivos presentes en las obras analizadas, como medio de superar la ideología de Vargas Llosa.

\section{Características de la obra}

La novelística y el teatro del autor peruano muestran cierta analogía en lo formal ${ }^{3}$; por ejemplo, en la dislocación temporal, la autoconciencia de la ficción y su cambiante punto de vista ${ }^{4}$. Además, se comparte la estructuración en términos de realidad y ficción, y de la concepción de autor que fundamenta el acto de escritura, entre otros. Como indica Angvik, refiriéndose a la teoría de la novela de Vargas Llosa ${ }^{5}$, la literatura es la expresión personal del autor con cualquier otra actividad extraliteraria o extraartística. La novela debe ser novela total, es decir, debe estar al servicio del autor y no de causa social alguna ${ }^{6}$.

3 Como se verá, la analogía es aun mayor en el plano funcional e ideológico.

4 Jacqueline Eyring Bixler, «Vargas Llosa's Kathie y el hipopótamo: The Theatre as a Self-Conscious Deception», Hispania 71 (1988): 254.

5 Tomamos como guía expositiva las concepciones de la narrativa vargasllosiana, ya que sobre el teatro de este autor es muy poco lo existente, para a partir de aquí establecer una analogía entre su novelística y su teatro, que con ayuda del análisis de Kathie y el hipopótamo, concrete tales afinidades.

6 Birger Angvik, «La teoría de la novela de Mario Vargas Llosa y su aplicación en la crítica literaria: desde la indeterminación metafórica del lenguaje teórico a la sobredeterminación categórica del lenguaje crítico», Káñina XVII, 2 (1993): 78 y 80. 
Para Vargas Llosa, escribir es un proceso estético que expresa la personalidad del autor, al modo de un autismo que cree en una separación entre lo particular y lo general ${ }^{7}$, entre la instancia particular llamada escritor y el todo social; el autor se centra en la creación de una coherencia interna y no de la veracidad de lo relatado que reduciría el realismo a la transmisión de la pluralidad de «la realidad» ${ }^{8}$. El autor es un artesano de la forma. ¿Y lo social?, ¿lo social (la realidad extraliteraria) proporciona, entonces, los contenidos?

Efectivamente, como expresa Angvik, la realidad proporciona los contenidos y el autor se queda en lo formal ${ }^{9}$. De modo idealista, Vargas Llosa separa forma y contenido. La forma es un juego estético sin valor extraliterario, o sea, sin valor referencial; es también la estructuración de significantes. Forma y realidad se identifican en el proceso de producción textual del autor. El contenido se ficcionaliza con la anulación de lo extraliterario.

En este marco, el escritor configura un lector que recibe y decodifica un mensaje ya formulado: el lector es un receptor pasivo ${ }^{10}$. Este lector es el complemento perfecto, por cuanto a él se le presenta un mundo escindido en realidad y ficción, el cual el lector no puede unificar, sintetizar, ya que esa síntesis implica un grado de actividad; el lector solo puede comprender (Verstehen), es decir, decodificar, pasar de un registro linguiístico a otro, el suyo, sin alterar la estructura. Los niveles de realidad y ficción determinan, por tanto, la técnica narrativa ${ }^{11}$.

7 Un rasgo per se ya muy posmoderno.

8 La realidad del autor. La coherencia intema refiere a la noción de novela autónoma de Vargas Llosa, que se enmarca en lo que él mismo denomina realismo total. Sin embargo, cómo subsiste una estética realista ante un autismo escritural. Solamente, de una manera, no hay tal autismo. Más adelante se verá esto. Véase: Angvik, 80-81.

9 Angvik, 79.

10 Angvik, 83.

11 Por ejemplo, en La ciudad y los perros: «Hay un personaje - ha dicho el autor-que representa (...) el mundo objetivo, que es la pura objetividad. que está visto desde afuera. Hay la antípoda, que es el caso del Boa, la pura interioridad. Está visto siempre como una conciencia en movimiento, como el flu jo de esa conciencia. Esta realidad permite incluir en ella el aspecto más tremendo, más fuerte, más violento de la realidad que se describe (...). Hay un tercer nivel, el de Alberto, que es más complejo de lo que se describe en la realidad, en sus dos fases, en sus dos caras. Alberto está visto desde el exterior y desde el interion, en: Helmy Giacoman y José Miguel Oviedo (Eds.), Homenaje a Mario Vargas Losa (Madrid: Las Américas, 1972) 29. 


\section{Realidad y ficción en Kathie y el hipopótamo}

Eyring indica que, en relación con la realidad y la ficción, el texto teatral de Kathie y el hipopótamo fusiona ambos elementos mediante la diversidad de roles que Kathie y Santiago asumen como amigos, amantes y parientes, en un juego de escenas ambiguas que crean la duda sobre la ficcionalidad o veracidad de estas escenas; y, por lo tanto, es inútil, según ella, el esfuerzo por distinguir entre lo real y lo ficticio, en el texto ${ }^{12}$. Sin embargo, la distinción entre lo real y lo ficticio es posible en tanto se acceda a una crítica ideológica del texto teatral.

Kathie y el hipopótamo, estructuralmente, la integra una serie de situaciones dramáticas que, a su vez, dan origen a un conjunto de fases y subfases ${ }^{13}$. La fase AAA se desarrolla desde la S1 (situación dramática uno) de la fase 1, que consiste en el hecho de que Juan le pide a Kathie ser novios, hasta la $\mathrm{S} 10$ de la fase AAA, en la cual Juan ya casado con Kathie, está borracho e intenta matar a Kathie o suicidarse él, debido a que Kathie le ha sido infiel. Veamos a continuación cómo se desarrolla cada fase a través de las diferentes situaciones.

La fase 1 se inicia con la S1, en la cual Kathie rechaza a Juan que le pide que sean novios (Kathie: 29-34); mientras que la fase 3S1 (Kathie: 42-44) presenta a Víctor pidiéndole a Kathie que se fuguen, pero ella rechaza el of recimiento porque está comprometida con Johnny. En la S2-fase 3, Víctor reclama a Kathie (Adèle) el haberse casado con Johnny, quien es el mismo Juan de que se hablaba en la $\mathrm{S} 1$-fase 1 , con lo cual fase 1 y fase 3 se conectan, conformando la fase A (Kathie: 46-56).

12 Mario Vargas Llosa, Kathie y el hipopótamo (Barcelona: Editorial Seix Barral, 1983) 256, 258 y 254; en adelante se indicará entre paréntesis el número de página.

13 Situaciones dramáticas son aquellas que generan un conflicto, tensión en la dinámica textual. Las fases son una serie de situaciones dramáticas y las subfases son las partes de la fase, en: Juan Villegas, La interpretación de la obra dramática (Santiago de Chile: Editorial Universitaria, 1971) 38-39. De hecho, la relación entre situación dramática, subfase y fase s e establece a nivel semántico. 
La fase A continúa su desarrollo con S3, en la cual Kathie cuenta a Santiago su tragedia matrimonial, mientras Juan (tablista en Waikiki) ingresa en escena y Ana (esposa de Santiago) se acerca a Santiago; y es en este punto que la fase A conecta con la fase 2, la cual tenía como S1 (Kathie: 38-40) una pelea matrimonial entre Ana y Santiago, debido a que él no la quiere; mientras que en la S2-fase 2, Ana se acerca a Santiago y le reclama a él su infidelidad. En esta situación, Kathie se transforma en Adèle, quien es alumna de Santiago y él se encuentra enamorado de ella (Kathie: 62-75). A partir de la fusión de la fase A con la fase 2, tenemos la fase AA.

Por su parte, en la fase 4-S1 (Kathie: 89-94), Ana y Juan son hijos de Kathie, los tres discuten porque Ana y Juan quieren que Kathie se vaya de viaje, pero ella no confía en ellos; también hacen referencia a Johnny. En la S2, Juan le pregunta a Kathie por el hijo de ellos (Juan es Johnny) lo cual conecta esta situación con la fase AA; también Ana y Juan (Johnnycito) odian a Kathie porque ella es la responsable de la muerte de su padre (Kathie: 100-103). Luego, la fusión de la fase 4 con la fase AA da la fase AAA: la macrofase.

La fase AAA continúa su desarrollo con la $\mathrm{S} 4$, en la cual Ana le dice a Mark Griffin que él se parece (en lo sexual) a los hipopótamos (Kathie: 95). En la S6 (Kathie: 103), Santiago discute con Ana. En la S7, Ana riñe con Santiago y Kathie (Adèle) ingresa en la conversación que gira alrededor de la capacidad sexual de Santiago (Kathie: 106-110). En S8, Juan y Kathie discuten porque él se da cuenta que ella le ha sido infiel; además, se evidencia que Kathie no aprecia a sus hijos (Kathie: 111-120). En S9 (Kathie: 120-129). Ana y Kathie hablan con Santiago sobre la vida de estudiante y sobre la vida intelectual de él; Santiago también expresa el fracaso de su relación con Adèle. En la S10, Juan regresa borracho a casa, Kathie le dice que su hija Alejandra es de él, pero que de Johnnycito no está segura que él sea el padre; al mismo tiempo Juan quiere matar a Kathie o suicidarse, pero no se atreve a realizar ninguno de los actos ( $\mathrm{Ka}$ thie: 129-135). 
La realidad, por consiguiente, está representada por Kathie Kennedy (quien dicta las vivencias de sus viajes) y por Santiago Zavala (quien escribe y da forma literaria a lo dictado por Kathie). La ficción recae en los papeles de Juan y Ana; sin olvidar que Santiago y Kathie - y sus transformaciones- participan también, por momentos, de esa ficción.

Tanto la realidad como la ficción en esta pieza teatral funcionan como cómplices, compenetrándose y fusionándose, para borrar los límites que las separan. Entre ficción y realidad, intratextual y ontológicamente hablando, no hay conflicto alguno, por tanto. Tal relación se hace conflictiva en función de la relación texto-sociedad (esto lo analizaremos más adelante).

\section{El caso de Lituma en Los Andes}

Lituma en Los Andes se desarrolla a partir de los ejes de realidad y ficción. El eje de la realidad es aquel en el cual se narra la problemática de los desaparecidos; el eje de la ficción corresponde a la narración, por parte de Tomás, de la historia de él y Mercedes (historia mediante la cual ambos, Lituma y Tomás se evaden del eje de realidad). El relato alterna la narración alrededor de estos dos ejes, hasta que en el epílogo el eje de ficción adquiere «realidad». Las situaciones que, a lo largo del texto, se suceden constantemente alternan realidad y ficción, en un proceso en el cual Vargas Llosa introduce una serie de categorías (fundamentalmente el relativismo) del paradigma posmoderno.

Si bien el eje de ficción sigue un patrón estable, dado dentro de una linealidad temporal y cumpliendo a la vez una función evasiva, en contraposición, el eje de realidad «juega» con el tiempo (aumentando la dislocación temporal propia de la alternancia de situaciones de realidad y ficción) de modo que la conexión entre diferentes situaciones se da mediante la conjugación de elementos que unen las desapariciones, a Casimiro Huarcaya y, además, la mención de 
la cantina de los brujos, como un medio de hacer coincidir diferentes momentos, alrededor de un espacio narrativo determinado.

La dislocación temporal también ocurre mediante la inclusión de microrrelatos sobre la vida de Dionisio y Adriana, por ejemplo. Así, el texto se mueve entre un pasado y un presente, que cierran cualquier posibilidad de establecer la continuidad de la realidad textual, perdida en la discontinuidad de lo particular narrado; es decir, el eje de la realidad es un juego de discontinuidades que se suman para crear un relato que se desarrolla a saltos, como puntos dentro de una recta, pero sin recta.

En este juego de alternancias la novela se desarrolla hasta que ambos ejes se encuentran y se genera un proceso de inversión de categorías. Se establece una semántica en donde la realidad y el concepto de verdad (clásicamente entendido) son desplazados por el relato evasivo de Tomás, el cual adquiere «valor de realidad» y, por consiguiente, la verdad hallada por Lituma con respecto a los desaparecidos pierde todo valor operativo y referencial (Lituma resuelve el misterio cuando ya el pueblo está prácticamente abandonado).

\section{La relación de la técnica realidad-ficción con el paradigma posmoderno}

Es importante delimitar el concepto de posmodernidad, ya que es una noción difícil de precisar por cuanto "permite la presencia y coexistencia de una gama de rasgos muy diferentes e incluso subordinados entre sí» $^{14}$. La posmodernidad parte de la afirmación de la pluralidad, a diferencia de la modernidad en la cual la tendencia era a la afirmación de la unidad, de lo general. Esta se entiende dentro del marco de aquellos «que tienen problemas o dudas con la moderni$\mathrm{dad}$, por aquellos que quieren someterla a prueba, y por aquellos que

14 Frederic Jameson, El posmodernismo ol a lógica del capitalismo avanzado (Buenos Aires: Paidós, 1992) 16. 
hacen un inventario de los logros de la modernidad, así como de sus dilemas no resueltos» ${ }^{15}$. A grandes rasgos, esto es la posmodernidad: una reacción dirían los posmodernos (yo diría una ilusión) contra el proyecto burgués del Iluminismo.

Entre las características de la epistemología posmoderna, está su relativismo; es decir, su hostilidad contra «la idea de una verdad única, objetiva, exclusiva, externa o trascendental» ${ }^{16}$. La verdad para los posmodernos es plural, subjetiva, y no pertenece a nadie en específico, ni a ninguna teoría. La verdad posmoderna tiene un valor particular. Dentro de este relativismo, se da un doble desplazamiento: de cosa a significado y de objeto a sujeto ${ }^{17}$. Tales desplazamientos reducen los procesos cognitivos a una hermenéutica, en la cual el conocimiento es simplificado a una operación de representación (Vorstellung) cultural (distinto en cada cultura) y a un ordenamiento semiótico de la realidad por parte del sujeto. Además, la labor de la razón (altamente valorada en la modernidad) se limita al manejo de una serie de códigos no-referenciales ${ }^{18}$.

Cabe preguntar cómo se establece la relación entre un paradigma epistemológico abstracto, como el posmoderno, y una técnica narrativa. La respuesta se halla en la función que cumple tal técnica, en la afirmación de X o Y valoraciones, o en el desprecio de A o B valoraciones. Por ejemplo, en Lituma en Los Andes hay una devaluación de lo racional, mediante el manejo del proceso investigativo alrededor de los desaparecidos. Dentro de este proceso, es evidente la asistematicidad en el método de investigación, ya que existe el planteamiento de una serie de pseudohipótesis de un altísimo valor especulativo:

15 Agnes Heller y Ferene Fehér, Políticas de la posmodernidad: ensayos de crítica cultural (Barcelona: Península, 1989) 149.

16 Emest Gellner, Posmodernismo, razón y religión (Barcelona: Paidós, 1994) 38.

17 Gellner, 41.

18 El posmodemismo es un collage, en el cual se asientan algunas contradicciones. Como ejemplo veamos: su afirmación del relativismo epistemológico es ya en sí una proposición de valor absoluto. Los posmodernos critican la modernidad como si se tratase de un fenómeno únicamente cultural, cuando en realidad es un fenómeno económico: la expansión del capital. 
primeramente, las desapariciones son el producto de la operación de Sendero Luminoso; luego, son consecuencia de las supersticiones religiosas o que las han cometido Adriana y Dionisio ${ }^{19}$, sin olvidar que, en algún momento, se cree que no hay explicación racional para las desapariciones (Lituma: 178). Todas estas «hipótesis» hacen de lo racional un simple ordenador semiótico de la realidad, la cual parece per se incognoscible.

Por otra parte, cuando ya Lituma resuelve el misterio (Lituma: 310 y ss.), la verdad alcanzada no le sirve, porque no hay pueblo. Además, enterarse de la verdad de los hechos lejos de darle satisfacción, le repugna y, por tanto, se desvaloriza la verdad al desconectársele, en esta novela, de la posibilidad de realizar alguna acción jurídico-policial.

También, respecto de las tantas hipótesis para explicar las desapariciones, éstas dependen estrechamente del marco cultural de quien las emite. Por ejemplo, dentro del marco cultural gitanesco de Adriana y Dionisio, la posible solución está llena de referencias a la superstición. Al marco referencial jurídico de Lituma corresponde una solución legal y Tomás ni siquiera se plantea el problema al evadirse en los recuerdos de Mercedes (lo cual puede interpretarse como una posición agnóstica que halla absurdo plantearse de por sí el problema).

De igual modo, en Lituma en Los Andes, la dislocación temporal acentúa un rasgo posmoderno que consiste en la preponderancia de las categorías espaciales sobre las temporale ${ }^{20}$, lo cual es apreciable en las alternancias de situaciones del eje de ficción con el eje de realidad. En el mismo sentido, la similitud de la historia de Dionisio y Adriana con la de Tomás y Mercedes introduce cierta circularidad al relato. El juego temporal se inserta en el eje de la realidad, mientras en el eje de la ficción el relato de Tomás se concibe como una

\footnotetext{
19 Mario Vargas Llosa, Lituma en Los Andes (Barcelona: Planeta, 1997) 43, 103 y 135 y ss.; en ade20 lante se indicará entre paréntesis el número de página.

Jameson, 40.
} 
linealidad temporal. Luego, el tiempo y su desarrollo lineal están ligados a la representación (Vorstellung), al discurso.

En Kathie y el hipopótamo es aun más claro cómo se establece una dependencia entre la representación y la realidad, por cuanto todo el texto dramático gira sobre la elaboración discursiva de los viajes de Kathie: todo, la realidad y la ficción se entremezclan en el juego del lenguaje, que solo es discernible en un análisis ideológico. Por tanto, somos embebidos por un texto que asume los datos biográficos de Kathie en la balanza de las diversas y diferentes perspectivas de cada actante. Kathie es asumida como madre, amante y esposa; yendo de la realidad a la ficción en cada uno de sus funciones, dentro de un tiempo que se mueve en el eje de la ficcionalidad, del pasado, al presente y al futuro de Kathie, en un oscilar de condensaciones y desplazamientos que difuminan la línea divisoria entre realidad y ficción, a la vez que escinden la relación referencial del lenguaje, como medio de establecer una ontología resquebrajada que fractura la unidad dialéctica de Ser y Pensamiento (lenguaje, discurso). Pero, en el eje de realidad (representado por Kathie Kennedy y Santiago Zavala) el tiempo transcurre sobre la linealidad articulatoria del lenguaje.

Mediante la asunción de una estructura narrativa dada en el empleo de un eje de realidad y otro de ficción, se introduce la desvalorización de lo racional, el perspectivismo, etc., rasgos posmodernos que se orquestan formalmente en función de la categoría de tiempo, puesto que es el tiempo que permite acceder a la conjunción entre el paradigma posmoderno y la técnica narrativa utilizada por Vargas Llosa, debido a que la destrucción de la linealidad temporal introduce, de por sí, un elemento irracional: el tiempo real, dialéctico, tiene un transcurrir lineal ${ }^{21}$. Por otra parte, el tiempo social, de la representación, permite jugar entre pasado, presente y futuro ${ }^{22}$. La separación

$21 \quad$ Esto es lo que algunos físicos denominan la flecha del tiempo. Al respecto puede consultarse: Paul Davies, «La flecha del tiempo», Investigación y Ciencia 314 (2002): 8-13.

22 Un futuro que solo es tal por referencia a un punto en el pasado, desde la cual se observa lo que en la realidad del texto es presente. Este juego temporal reduce la temporalidad a un circuito pasadopresente. 
de ambas temporalidades (que son un par dialéctico) en la realidad textual es el reflejo de una gnoseología propia del pensamiento (Meinen) posmoderno.

\section{El sustrato ideológico presente en la técnica narrativa realidad- ficción}

Hemos establecido la relación entre posmodernidad y la técnica de Vargas Llosa. Pero además, es preciso ubicar esta relación en la cuestión política. Hay que preguntarse cuál es su funcionamiento en el panorama político actual, y cómo se entronca lo literario con el fenómeno neoliberal.

Empecemos con Kathie y el hipopótamo. Para acceder al nivel ideológico es necesario confrontar el mundo dramático que nos ofrece el inicio del texto, con el mundo del final del texto, para luego considerar los factores que conducen en una u otra dirección (si la hay ${ }^{23}$. Así, el texto analizado empieza y termina con aquello que este tiene por realidad: Kathie y Santiago escribiendo en la buhardilla, a la vez, que siguen recurriendo a la ensoñación como medio de evasión. En esta perspectiva, el texto en cuanto posible resolución simbólica de las contradicciones sociales ${ }^{24}$, no adopta tales contradicciones en bruto (en su materialidad), sino que las asume en una perspectiva de clase hegemónica, lo cual hace que las contradicciones que el proceso de producción textual integra, aparezcan subrepticiamente disueltas. O sea, las contradicciones no se aprehenden en el binomio realidad-posibilidad ${ }^{25}$, sino que se representan en la conjun-

\footnotetext{
$2 \overline{23}$ Villegas, 60.

24 La ideología es un fenómeno semiótico, mas no se agota en lo discursivo y se extiende a instancias no discursivas que deforman la praxis. Por lo tanto, el signo y el contexto se encuentran inextricablemente unidos, por lo que el signo deviene, también, escenario de la lucha de clases. en Terry Eagleton, Ideología: una introducción (Barcelona: Paidós, 1997) 245.

El empleo del binomio realidad-posibilidad (que son categorías dialécticas) implica la necesidad de acceder a un esquema representacional propositivo, que no se dedique a «pintar» una realidad, sino que aprehenda el posible devenir del Ser. Para una explicación de la dialéctica y su empleo en el análisis literario, ver: Roy Alfaro Vargas, «Relación literatura-sociedad. Una aproximación teórica»,
} 
ción realidad-ficción, con un predominio de la ficcionalidad; en cuanto espacio donde es posible el «cambio». Con esto, el texto cierra la capacidad de cambio social, en tanto facultad del sujeto histórico ${ }^{26}$. Por consiguiente, este texto en el nivel ideológico supone:

- un cierre de la noción de cambio dentro del concepto de ensoñación, dado en el acto de representación de la novela que escriben Kathie y Santiago; y

- la fijación de una realidad anclada en la división social del trabajo (representado esto en la relación laboral de Kathie y Santiago) y en cuanto «unión cómplice» de burguesía y proletariado en el marco de la representación (Vorstellung) novelesca emprendida por ellos.

A nivel epistemológico, esta pieza teatral lleva implícita una separación entre objeto (realidad) y los personajes Kathie y Santiago (el sujeto), los cuales son incapaces, mediante la praxis, de proponer algo más que el simple acto de representación literaria, como medio para postular una posibilidad social que vaya más allá de lo representacional, hacia la postulación utópica ${ }^{27}$. Kathie y Santiago no pueden conocer la realidad (solo codificarla); luego, no pueden transformarla. El texto mantiene una realidad análoga entre el inicio y el final de la obra y, por consiguiente, se legitima un status quo, ya que no es transformable.

Revista de Ciencias Sociales II, 108 (2005): 71-78; «Sociología dialéctica de la literatura: cuestión de método», Revista de Ciencias Sociales III-IV, 109-110 (2005): 151-156; y «La sociología crítica de Henri Lefebvre», Revista de Ciencias Sociales III-IV, 113-114 (2006): 97-104.

26 Esto convierte al lector en un elemento pasivo que ayuda a presentar la isotopía textual como el sistema coherente de los elementos semánticos jerarquizados siguiendo el avance del tiempo operativo actualizador, en: Moshe Tabachnick, «Sur la géométrisation de l'espace narratif dans le parcours interprétatif du texte littéraire», Semiótica 154, 1-4 (2005): 41 . Con esto, se quiere cercar al lector dentro de lo que se ha denominado la cronogénesis tabachnickiana, en donde el hombre pierde su responsabilidad histórica; véase: Roy Alfaro Vargas, «Antropologías literarias: prolegómenos a la praxis textual», Praxis 59 (2007): 7-17. 
Con respecto a Lituma en Los Andes, se hace un cierre del concepto de verdad clásico, en la noción de relativismo que introduce un Ser escindido y que, como ya se vio, implica una alteración de las categorías de tiempo y de espacio mediante la creación de una estructura categorial donde se acentúa el yo (individual o colectivo) como interpretante, como hermeneuta. En el caso de Lituma, esta hermenéutica corresponde a una visión peyorativa del concepto de verdad. Es en este punto en que el texto, en tanto signo, se inserta en el espacio de la lucha de clases, ya que, al igual que en Kathie y el hipopótamo, la realidad solamente es codificable; es decir, esta realidad se circunscribe, por tanto, a la elaboración discursiva de una representación (Vorstellung) separada de su valor referencial.

Esta arreferencialidad es expresión clara de los signos de los tiempos posmodernos, al modo derridiano ${ }^{28}$ en donde la epistème cede a lo dóxico, en un hipertextual juego en el cual un significante remite a otro y a otro per secula seculorum. A la vez, se le da la espalda al proceso de globalización y al consecuente predominio del capital financiero ${ }^{29} \mathrm{y}$, por tanto, a la expansión de la ideología neoliberal.

Echamos mano de un término de Hernán López, el de liberalismo posmoderno ${ }^{30}$. Este término pone en relación dos conceptos en apariencia excluyentes: por un lado, la noción de liberalismo conlleva, en el credo smithiano, la libre competencia como motor del desarrollo social y económico; es decir, el laissez faire, laissez passer como fundamento de la autorregulación del mercado, donde la ley del más fuerte guía el proceso productivo. En este esquema, cuando es necesario acabar con el competidor por un espacio en el mercado,

28 Ver Jacques Derrida, L'écriture et la différence (París: Éditions du Seuil, 1967); y De la gramatologie (París: Minuit, 1967). Además, para una crítica de la concepción simbólica (representacional) del pensamiento, véase: John-Michael Kuczynski. «The Concept of a Symbol and the Vacuousness of the Symbolic Conception of Thought», Semiótica 154, 1/4 (2005) 243-263. Para un análisis del capitalismo actual, ver: Wim Dierckxsens, Del neoliberalismo al poscapitalismo (San José, Costa Rica: DEI. 2000). Occidente 210 (1998): 115. 
no hay lugar para la solidaridad, ya que, la totalización depredadora, que sufre la vida cotidiana a manos del mercado, insita a tomar al Otro como un obstáculo en un proyecto de vida tendiente hacia la consecución del «éxito» (entendido en términos burgueses). Por otro lado, tenemos la posmodernidad con su rescate de la différence, o sea, su énfasis en abolir los macrorrelatos totalizantes (excepto la totalización dada por el mercado) en búsqueda de una interrelación dialógica de las diversas manifestaciones identitarias, en un movimiento que rechaza cualquier ideología o cualquier ideario, que implique lo general, lo universal, por considerarse homogenizante y atentar contra la particularidad fenomenológica de las comunidades identitarias.

Textos como Lituma en Los Andes o Kathie y el hipopótamo son la expresión estética de la contradicción entre liberalismo y posmodernidad que, en tanto ideología funciona como un lubricante sexual que alivia la dolorosa penetración neocolonial del capital transnacional, en los países latinoamericanos. Esto en un proceso que desplaza y condensa la problemática socioeconómica, hacia la lógica autista de la ingeniería identitaria posmoderna, desconocedora de lo general y de las masas que cada día aumentan las estadísticas de pobreza, por culpa de las políticas impulsadas por los países del primer mundo y sus organismos financieros (FMI, BID), a través de un macrorrelato que sí es hipócritamente válido para los posmodernos: el de la explotación capitalista.

\section{Esquemas socializantes $^{31}$ : valoraciones y patrones cognitivos da- dos en los textos estudiados}

Vargas Llosa asigna, en su concepción de la literatura, al lector un papel de decodificador pasivo del texto literario ${ }^{32}$, lo cual guarda

\footnotetext{
31 La noción de esquemas socializantes ha sido planteada en las obras citadas anteriormente de Vargas, «Relación ....»y «Sociología ...».

Angvik, 83.
} 
coherencia la ideología neoliberal que sirve de sustrato a los textos estudiados. Tal coherencia reside en la necesidad de que su opinión política sea aceptada por aquellos lectores, que hacen una lectura positi$\mathrm{va}^{33}$ de la literatura. Se establece subrepticiamente una antropología formal, en donde se deposita un valor funcional reaccionario ${ }^{34}$.

Dentro de esta ideación del lector, el autor incorpora de modo estético ciertas caracterizaciones o jerarquizaciones, que asumidas sin una mediación reflexiva se establecen como pautas de socialización, por medio de la estructuración valorativa ordenadora de la realidad textual. Por ejemplo: en Lituma en Los Andes, el eje de la ficción desenvuelve el «intenso» romance entre Tomás y Mercedes; eje que $a$ posteriori, en el epílogo, es sobrevalorado, debido a que el discurso amoroso del ayudante de Lituma deviene real. Con esto, el proceso racional para resolver el problema de los desaparecidos y su resolución son puestos entre paréntesis, y, por consecuencia, se da una valoración positiva de la emoción irracional (y codependiente) del discurso de Tomás, por sobre la solución del asunto policíaco que ocupaba a ambos policías: la verdad deja de tener solidez alguna. Y al ser la verdad una noción desdeñable, entonces el valor de la existencia recae en lo vivencial. Luego, lo racional es lo no bueno y lo irracional lo bueno, ya que, nadie afirmaría un valor no aplicable a sí mismo, y si se aplica a sí mismo, es porque es bueno. He aquí lo ético camuflado en lo estético.

En Kathie y el hipopótamo la dislocación del tiempo mediante los muchos papeles de Kathie y Santiago evidencian una reordenación de la sucesión temporal, que hace del tiempo una circularidad ${ }^{35}$, en la cual se reafirma la imposibilidad de la acción dentro de un espacio que no transcurre. La transformación social adquiere el status de discurso. La represión absoluta de la contestariedad en una máxima

33 Para ampliar la noción de lectura positiva, véase: Vargas, «Antropologías ...», 10.

34 Vargas, "Antropologías ...", 13.

35 Entre las características de la novela vargasllosiana, está el deseo de crear una temporalidad circular; en Angvik, 81. 
contradictoria: un mundo literario que se mueve sobre dos ejes (realidad y ficción), pero no cambia.

Aunque Vargas Llosa conciba su producción como total y autónoma ${ }^{36}$, es imposible que el lenguaje no sea referencial y no satisfaga alguna causa social y a los contextos de escritura y de lectura. Habría que ser un perfecto idiota latinoamericano para pensar lo contrario. La literatura siempre satisface algún interés no literario.

\section{Conclusiones}

El binomio realidad-ficción es la respuesta formal al imperativo de Vargas Llosa de imponer, a nivel epistemológico, su visión neoliberal, con cierto aire posmoderno. Para esto, se vale de una conceptualización de la noción de lector, como un destinatario pasivo del mensaje codificado en el texto literario y, por consiguiente, caracterizado como un ente manipulable. Seguir esta estrategia de escritura, el autor se vale de la dislocación temporal como fundamento para incorporar el perspectivismo, el relativismo, lo irracional, y sobre todo, el ataque a la noción clásica de verdad y a la relación dialéctica existente entre Ser y Pensamiento, para reducir los procesos, tanto cognitivos como epistemológicos, al fenómeno de representación, al discurso. Los textos analizados apuntan a la legitimización del statu quo de la globalización, por vía de la negación (Verneinung) ${ }^{37}$ de la pobreza engendrada por las políticas de los neoliberales.

36 Para Vargas Llosa, la novela debe ser total y autónoma; o sea, la literatura debe estar al servicio del autor, dentro de un ambiente de coherencia. Por lo tanto, la literatura, en general, y sus manif estaciones particulares no deben seguir ninguna causa social, ni regirse por la lógica del devenir del referente, véase Angvik, 80-81.

37 Negación (Vermeinung) en sentido psicoanalítico, es decir, como mecanismo de defensa. 